\title{
PENGGUNAAN MIND MAP DALAM MATA KULIAH ANATOMI FISIOLOGI MANUSIA SEBAGAI INTEGRASI BERBAGAI KONSEP UNTUK MENINGKATKAN HASIL BELAJAR MAHASISWA TA 2014/2015
}

\author{
Nurkhairo Hidayati \\ Program Studi Pendidikan Biologi FKIP Universitas Islam Riau \\ Email: khairo_vi@yahoo.com \\ Diterima 14 September 2015 disetujui 25 Oktober 2015
}

\begin{abstract}
Human anatomy and physiology course has a variety of interrelated or integrate concepts and causal relationship, so that the concepts easier to understand student learning process is done using a mind map. The role of the mind map is very important because it helps the students categorize the material in accordance with the idea that it is easier to understand. Mind map is a way of noting a fun, easy way to absorb and release information and new ideas. Mind map using sign or symbol which is equipped with a color. Signs or symbols that are used as well as color influence strengthening student understanding and memory. Each concept can be expressed with one word idea and visualized with a symbol or image. This research aims to improve student learning outcomes in Human Anatomy Physiology using mind map. This research is a classroom action research that begins with: 1) planning action, 2) implementation, 3) observation, 4) reflection. The results showed an increase in student learning outcomes. The first cycle, the average student learning outcomes is 66, 32. The second cycle, the average student learning outcomes 70,35 and increased again in third cycle to 76.79. Based on the results concluded that the use of mind mapping can improve learning outcomes of students in the subject of Human Physiology Anatomy.
\end{abstract}

Keywords: mind map, learning outcomes, Human Physiology and Anatomy

\section{PENDAHULUAN}

Pendidikan mempunyai peranan yang sangat besar dalam pembentukan karakter, perkembangan ilmu dan mental seorang anak yang nantinya akan tumbuh menjadi seorang manusia dewasa yang akan berinteraksi dan melakukan banyak hal terhadap lingkungannya, baik secara individu maupun sebagai makhluk sosial. Peranan pendidikan dapat tercapai dengan adanya proses belajar dan mengajar. Proses mengajar dan belajar maka akan menimbulkan keterkaitan antara keduanya yaitu terjadinya pembelajaran. Pembelajaran adalah serangkaian kegiatan yang dirancang untuk memungkinkan terjadinya proses belajar mengajar pada siswa

Kegiatan pembelajaran terdapat kegiatan memilih, menetapkan, dan mengembangkan strategi yang optimal untuk mencapai hasil pembelajaran yang diinginkan. Adanya faktor yang juga mempengaruhi hasil belajar adalah penggunaan media pembelajaran (Gagne, 2010). Proses pembelajaran merupakan proses komunikasi dan berlangsung dalam suatu sistem, maka media pembelajaran menempati posisi yang cukup penting sebagai salah satu komponen sistem pembelajaran. Komunikasi tidak akan terjadi dan proses pembelajaran sebagai proses komunikasi juga tidak akan bisa berlangsung secara optimal apabila media pembelajaran tidak ada. Media pembelajaran merupakan kompo-nen integral dari sistem pembelajaran.

Munculnya berbagai media pembelajaran saat ini sebagai upaya untuk mengoptimalkan kegiatan pembelajaran. Agar dalam melakukan kegiatan 
pembelajaran didapatkan hasil yang efektif dan efisien tentu saja diperlukan prinsipprinsip pembelajaran tertentu yang dapat melapangkan jalan ke arah keberhasilan. Salah satu media pembelajaran yang bisa digunakan adalah mind map (peta pikiran).

Pemetaan pikiran mirip dengan outlining, namun lebih menarik secara visual, serta pembuatannya melibatkan kedua belahan otak. Kekuatan istimewa pemetaan pikiran adalah melatih otak melihat secara menyeluruh sekaligus secara terperinci dan dalam hal ini terjadi integrasi antara logika dan daya khayal. Tony Buzan bersama Michael Gelb pada tahun 1960-an mengembangkan pemetaan pikiran sebagai pendekatan yang melibatkan seluruh otak, serta telah mengajarkannya kepada ribuan orang. Pemetaan pikiran telah banyak digunakan di dunia pekerjaan maupun pendidikan sampai saat ini.

Pemetaan pikiran merupakan catatan nonlinier dengan unsur-unsur: (1) fokus pusat yang berisi citra atau lambang gambar masalah atau informasi yang dipetakan, diletakkan di tengah halaman; (2) gagasan dibiarkan mengalir bebas tanpa penilaian; (3) kata-kata kunci digunakan untuk menyatakan gagasan; (4) hanya satu kata kunci ditulis perbaris; (5) gagasan kata kunci dihubungkan ke fokus pusat dengan garis: (6) warna digunakan untuk menerangi dan menekankan pentingnya sebuah gagasan; (7) gambar dan lambang digunakan untuk menyoroti gagasan dan merangsang pikiran agar membentuk kaitan yang lain. Penggunaan garis, panah atau lambang digunakan untuk mengaitkan beberapa gagasan atau konsep, Pengembangan sistem lambang yang merupakan bentuk singkat untuk berkomunikasi dengan diri kita sendiri. Sistem manapun yang cocok, karena pemetaan pikiran adalah cara kita memanfaatkan pikiran secara maksimal.

Peranan mind map sangat penting pada Mata kuliah Anatomi Fisiologi Manusia, karena dalam mata kuliah Anatomi Fisiologi Manusia memuat beberapa konsep yang saling terkait dan merupakan hubungan sebab akibat. Peta pikiran yang dibuat dapat membantu mahasiswa dalam proses belajar mengajar. Tanda atau simbol-simbol yang digunakan serta warna sangat mempengaruhi dalam penguatan pemahaman dan memori. Tiap konsep dapat dinyatakan dengan satu kata gagasan dan sedapat mungkin divisualkan dengan satu lambang atau gambar.

Mind map merupakan cara mencatat yang menyenangkan, cara mudah menyerap dan mengeluarkan informasi dan ide baru dalam otak (Buzan, 2007). Mind map adalah cara mencatat yang kreatif dan efektif, cara mudah memasukkan dan mengeluarkan informasi dalam otak, mind map menggunakan warna, simbol, kata, garis lengkung dan gambar yang sesuai dengan cara kerja otak.

Berdasarkan latar belakang tersebut dilakukan penelitian dengan judul penggunaan mind map dalam mata kuliah anatomi fisiologi manusia sebagai integrasi berbagai konsep untuk meningkatkan hasil belajar mahasiswa TA 2014/2015

\section{METODE}

Penelitian dilaksanakan pada semester genap TA 2014/2015, subjek penelitian adalah mahasiswa semester 6C yang mengikuti mata kuliah Anatomi Fisiologi Manusia dengan jumlah 39 orang. Jenis penelitian merupakan Penelitian Tindakan Kelas (PTK) dengan menggunakan Mind Map. PTK merupakan penelitian tindakan dalam bidang pendidikan yang dilaksanakan dalam kawasan kelas dengan tujuan untuk memperbaiki dan meningkatkan kualitas pembelajaran. PTK yang dilakukan meliputi tahap perencanaan, pelaksanaan, pengamatan dan refleksi.

Teknik pengumpulan data dilakukan melalui tes, observasi, dan dokumentasi. Instrumen yang digunakan untuk memperolah data hasil belajar adalah tes tertulis dengan menggunakan tipe soal 
pilihan ganda, Isian singkat, benar-salah dan essay. Data-data yang diperoleh dari penelitian kemudian diolah dengan analisis diskriptif untuk menggambarkan keadaan peningkatan pencapaian hasil belajar tiap siklus dan untuk menggambarkan keberhasilan pembelajaran. Analisis data secara deskriptif dengan melihat daya serap, ketuntasan individu, dan ketuntasan klasikal.

\section{HASIL DAN PEMBAHASAN}

Penggunaan mind map dalam proses pembelajaran membantu mahasiswa dalam mengaitkan konsep sehingga pengetahuan yang diterima lebih mudah dipahami mahasiswa. Gambar 2 berikut ini ditampilkan beberapa contoh mind map yang telah digunakan dalam proses pembelajaran mata kuliah Anatomi Fisiologi Manusia.

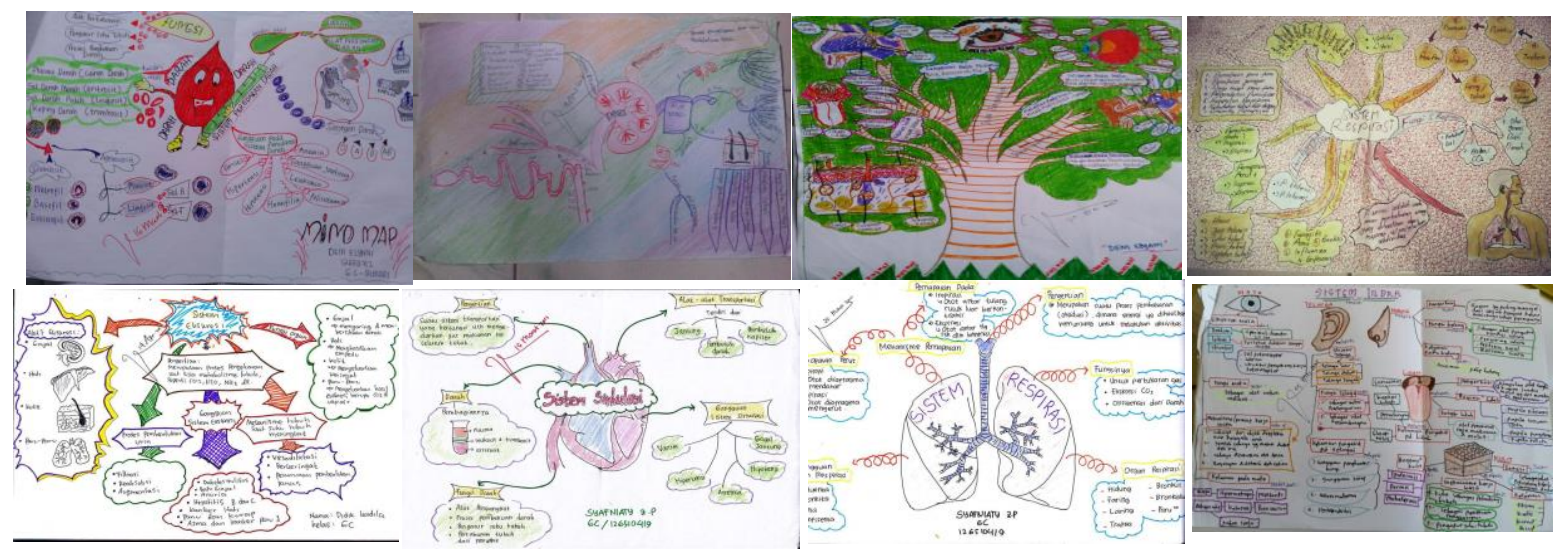

Gambar 2. Contoh Mind Map dalam Proses Pembelajaran

Tabel 1. Hasil belajar mahasiswa pada mata kuliah Anatomi Fisiologi Manusia

\begin{tabular}{ccccc}
\hline Interval & $\begin{array}{c}\text { Nilai } \\
\text { (Huruf) }\end{array}$ & $\begin{array}{c}\text { Siklus 1 } \\
(\mathbf{\%})\end{array}$ & $\begin{array}{c}\text { Siklus 2 } \\
(\boldsymbol{\%})\end{array}$ & $\begin{array}{c}\text { Siklus 3 } \\
(\boldsymbol{\%})\end{array}$ \\
\hline $86-100$ & $\mathrm{~A}$ & $3(7,69)$ & $4(10,26)$ & $11(28,21)$ \\
$80-85$ & $\mathrm{~A}-$ & $9(23,08)$ & $2(5,13)$ & $7(17,95)$ \\
$76-79$ & $\mathrm{~B}+$ & $1(2,56)$ & $7(17,95)$ & $5(12,82)$ \\
$70-75$ & $\mathrm{~B}$ & $6(15,38)$ & $10(25,64)$ & $10(25,64)$ \\
$66-69$ & $\mathrm{~B}-$ & $3(7,69)$ & $5(12,82)$ & $3(7,69)$ \\
$60-65$ & $\mathrm{C}+$ & $6(15,38)$ & $8(20,51)$ & $1(2,56)$ \\
$56-59$ & $\mathrm{C}$ & $2(5,13)$ & $3(7,69)$ & - \\
$50-55$ & $\mathrm{C}-$ & $2(5,13)$ & & $1(2,56)$ \\
$45-49$ & $\mathrm{D}$ & $1(2,56)$ & & - \\
$0-44$ & $\mathrm{E}$ & $6(15,38)$ & & $1(2,56)$ \\
\hline Daya Serap & & 66,32 & 70,35 & 76,78 \\
\hline Ketuntasan Individu & 28 & 36 & 37 \\
\hline Ketuntasan Klasikal & & 71,79 & 92,31 & 94,87 \\
\hline
\end{tabular}

Setelah dilakukan proses pembelajaran menggunakan mind map, mahasiswa diminta mengerjakan tes untuk mengetahui tingkat pemahaman mereka. Hasil belajar mahasiswa tersebut dapat dilihat pada Tabel 1. Berdasarkan Tabel 1 dapat diketahui bahwa terjadi peningkatan hasil belajar mahasiswa pada setiap siklusnya. Siklus 1 rata-rata hasil belajar mahasiswa adaah 66,32 dengan jumlah 
siswa yang bisa mencapai nilai minimal C sebanyak 28 orang. Siklus 1 terdapat 3 orang yang memperoleh nilai $\mathrm{A}$, sedangkan yang mendapat nilai A- berjumlah 9 orang. Jumlah mahasiswa yang memperoleh nilai $\mathrm{B}+$ adalah 1 orang, yang memperoleh nilai $\mathrm{B}$ sebanyak 6 orang dan yang memperoleh nilai B- sejumlah 3 orang. Siklus 1 masih ditemukan $15,38 \%$ siswa yang nilainya berada pada interval $0-44$, kondisi ini terjadi karena mereka masih penyesuian dengan penggunaan mind map

Siklus 2 rata-rata hasil belajar mahasiswa adalah 70,35 , dari 39 orang mahasiswa yang mengikuti proses pembelajaran, hanya ada 3 orang mahasiswa yang belum mampu memperoleh nilai $\mathrm{C}+$. Siklus 2 hasil belajar siswa terjadi peningkatan dibandingkan dengan siklus 1 , meskipun terjadi peningkatan hasil belajar, namun jika diihat dari perolehan nilai maka pada beberapa interval nilai terjadi penurunan persentase. Sebagai contoh, persentase mahasiswa yang memperoleh nilai A- pada siklus 1 adalah 23,08\% sedangkan pada siklus 2, persentase mahasiswa yang memperoleh nilai A- adalah $5,13 \%$. Berdasarkan Tabel 1 juga dapat diketahui bahwa pada siklus 3, rata-rata hasil belajar adalah 76,78 dengan ketuntasan klasikal sebesar 94,87\%. Pada siklus ini, jumlah siswa yang memperoleh nilai $\mathrm{A}$ sebanyak 11 orang, nilai A- sebanyak 7 orang. Siklus 2 tidak ada mahasiswa yang mempeoleh nilai C-, tetapi pada siklus 3 terdapat 1 orang siswa yang memperoleh nilai $\mathrm{C}$ -

Berdasarkan hasil analisis data dapat diketahui bahwa dengan penggunaan mind map terjadi peningkatatan hasil belajar mahasiswa secara bertahap mulai dari siklus 1 hingga siklus 3 . Siklus 1, rata-rata pencapaian hasil belajar adalah 66,32 . Siklus 2 , rata-rata hasil belajar adalah 70,35 dan pada siklus 3 adalah 76,78. Peningkatan hasil belajar ini disebabkan karena penggunaan mind map. Menurut Buzan (2004), mind map merupakan cara mencatat yang kreatif dan efektif, cara mudah memasukkan dan mengeluarkan informasi dalam otak, mind map menggunakan warna, simbol, kata, garis lengkung dan gambar yang sesuai dengan cara kerja otak.

Siklus 1, masih ditemukan mahasiswa yang mendapat nilai di bawah 45. Upaya yang dilakukan untuk memperbaiki kondisi ini, peneliti menunjukkan ke mahasiswa cara membuat mind map yang baik agar semua konsep yang penting dituangkan dalam mind map tersebut. Menurut Buzan (2007), cara membuat mind map adalah (1) menyiapkan kertas kosong, mulai dari bagian tengah; (2) pada bagian tengah tulis topik utama, dapat juga menggunakan gambar atau foto; (3) menghubungkan cabang-cabang utama ke topik utama dan hubungkan cabang-cabang utama pada ranting-ranting yang merupakan sub topik utama; (4) menggunakan garis hubung yang melengkung; (5) menggunakan warna; (6) menggunakan kata kunci pada setiap garis hubung; (7) menggunakan gambar

Siklus 2, terjadi peningkatan hasil belajar dengan daya serap $70,35 \%$, jika dicermati lagi tabel 1 maka terlihat 3 orang mahasiswa yang nilai berada 56-59, sedangkan yang lainnya sudah mencapai nilai minimal $\mathrm{C}+$. Proses pembelajaran, mahasiswa menggunakan mind map untuk membamtu menghubungkan antar konsep, dengan cara ini, mahasiswa lebih mudah memahami materi anatomi fisiologi manusia. Ada beberapa fungsi mind map dalam proses pembelajaran yaitu mempermudah dalam mengingat informasi, mempermudah memperoleh ide, belajar menjadi efektif dan efisien, menjadikan hidup lebih kreatif, dan dapat megatur kehidupan sehari-hari.

Berdasarkan hasil analisis data pada siklus 3, ketuntasan klasikal mencapai $94,87 \%$, artinya hampir seluruh mahasiswa sudah dapat mencapai batas minimal nilai yang ditetapkan yaitu 60. Berdasarkan tabel 1 , ada 2 orang mahasiswa yang belum 
mencapai batas minimal tersebut. Menurut Buzan (2004), terdapat beberapa kelebihan mind map yaitu dapat digunakan untuk mengorganisasikan ide-ide yang muncul di kepala, proses menggambar pada mind map bisa memunculkan ide-ide yang lain, dan diagram yang sudah terbentuk bisa menjadi panduan untuk menulis

\section{SIMPULAN}

Beradasarkan hasil penelitian dapat disimpulkan bahwa penggunaan mind map sebagai integrasi berbagai konsep dapat meningkatkan hasil belajar mahasiwa pada mata kuliah anatomi fisiologi manusia TA 2014/2015. Keefektifan penggunaan mind map, mahasiswa dibiasakan membuat mind map, agar mind map yang telah dibuat mahasiswa dapat berperan optimal dalam proses pembelajaran harus diberikan penilaian

\section{DAFTAR PUSTAKA}

Arikunto, Suharsimi, (2007). Penelitian Tindakan kelas. Jakarta: Bumi Aksara

Buzan, Tony. (2004). Mind Map Untuk Meningkatkan Kreativitas. Jakarta: Gramedia

Buzan, Tony. (2007). Buku Pintar Mind Map Untuk Anak. Jakarta: Gramedia
Gagne. (2010). Konsep pembelajaran Anak. Jakarta:Bumi Aksara

Matthew, B Miles dan A, Michael Huberman. (2001). Analisis Data

Kualitatif. Jakarta: Universitas Indonesia

Mulyasa, E. (2009). Praktik Penelitian Tindakan Kelas. Bandung: Rosda

Olivia, F. (2008). Gembira Belajar dengan Mind Mapping. Jakarta: Elex Media Komputindo.

Sagala, Saiful. (2009). Konsep dan Makna Pembelajaran. Bandung: Alpabeta.

Sanjaya, Wina. (2006). Pembelajaran Dalam Implementasi Kurikulum Berbasis Kompetensi. Jakarta: Kencana Prenada Media Group

Slameto. (1991). Belajar Faktor-Faktor Yang Mempengaruhinya. Jakarta: Rineka Cipta

Sugiyono. (2008). Metode Penelitian Pendidikan. Bandung: Alfabeta.

Svantesson, Ingemar. (2004). Learning Maps and Memori Skills. Jakarta: Gramedia

Trianto. (2009). Mendesain Model Pembelajaran Inovatif-Progresif. Jakarta: Kencana Prenada

Uno, B. Hamzah. (2007). Model Pembelajaran. Jakarta: PT. Bumi Aksara 